Original article

Section: Food Quality and Functionality

\title{
Hydrolyzed Collagen from Salmon Skin Increases the Migration and Filopodia Formation of Skin Keratinocytes by Activation of FAK/Sre Pathway
}

\author{
Wanwipha Woonnoi ${ }^{1}$, Lalita Chotphruethipong ${ }^{2}$, Supita Tanasawet ${ }^{1}{ }^{\circledR}$, Soottawat Benjakul ${ }^{\circledR}$, \\ Nuthathai Sutthiwong ${ }^{4}$, Wanida Sukketsiri ${ }^{*} *$ (i)
}

\author{
${ }^{1}$ Division of Health and Applied Sciences, Faculty of Science, Prince of Songkla University, Hat Yai, Songkhla 901 10, Thailand \\ 2International Center of Excellence in Seafood Science and Innovation, Faculty of Agro-Industry, \\ Prince of Songkla University, Hat Yai, Songkhla 90110, Thailand \\ ${ }^{3}$ Department of Food Technology, Faculty of Agro-Industry, Prince of Songkla University, Hat Yai, Songkhla 90110, Thailand \\ ${ }^{4}$ Expert Centre of Innovative Health Food (InnoFood), \\ Thailand Institute of Scientific and Technological Research (TISTR), Khlong Luang, Pathum Thani 12120, Thailand
}

Key words: cell culture, keratinocyte stem cells, marine collagen, re-epithelialization, skin barrier, wound healing

Previous studies reported hydrolyzed collagen increase cell proliferation and migration involved in the wound repair process. Nevertheless, the knowledge related with wound repair mechanism of hydrolyzed collagen from salmon skin (HCSS) has not been fully elucidated. Therefore, this study aimed to elucidate the effects of HCSS on the migration of keratinocyte HaCaT cells. Additionally, its molecular mechanism through cell division control protein 42 (Cdc42), Ras-related C3 botulinum toxin substrate 1 (Rac1), and Ras homolog family member A (RhoA) via focal adhesion kinase (FAK)-steroid receptor coactivator (Src) regulation and keratinocyte stem cells (KSCs) markers were also evaluated. After 24 h of incubation, keratinocyte proliferation was detected by 3-(4,5-dimethylthiazol-2-yl)-2,5-diphenyltetrazolium bromide (MTT) and double stranded DNA (dsDNA) assays, and by determining the total cellular protein content. Keratinocyte migration and filopodia formation were measured by wound healing assay and phalloidin-rhodamine staining, respectively. The migratory related proteins were evaluated by western blot analysis. HCSS had a high content of hydrophobic amino acids and imino acids. HaCaT cell proliferation and migration were significantly increased in response to HCSS at the concentration of $100-1000 \mu \mathrm{g} / \mathrm{mL}$. The formation of filopodia was subsequently increased in response to HCSS at concentrations of $100-1000 \mu \mathrm{g} / \mathrm{mL}$. Moreover, HCSS upregulated Cdc42, Rac1, and RhoA protein expression and activated the phosphorylation of FAK and Src pathway. HCSS at the concentration of 100-1000 $\mu \mathrm{g} / \mathrm{mL}$ could trigger stemness by increased KSC markers, including keratin 19 and $\beta$-catenin expression. This study has demonstrated that HCSS induces proliferation and migration of keratinocytes, subsequently promotes the second phase of wound healing process by FAK-Src activation and also increases the KSC properties.

\section{INTRODUCTION}

Human skin, especially the epidermis, is a major barrier against noxious pollutants which could be impaired by various factors including ultraviolet (UV), chemical and mechanical stimuli [Baroni et al., 2012]. Furthermore, the renewal of skin in epidermis layer is important for human skin barrier function [Baroni et al., 2012; Wickett \& Visscher, 2006]. In response to skin damages, the renewal process and cell proliferation were observed in the UV, heat, and wound-induced skin injury [Wikramanayake et al., 2014]. Keratinocyte stem cells (KSCs) regulate epidermal renewal and skin homeostasis. In addition, KSCs can produce extracellular matrix (ECM) components, cytokines, and growth factors in both normal function and response to skin injury [Fuchs, 2008; Pincelli
\& Marconi, 2010; Sotiropoulou \& Blanpain, 2012]. The decrease of KSCs numbers and activities leads to the epidermal barrier impairment [Yang et al., 2019a]. Besides, keratinocyte proliferation and migration are accepted to play a major role in the re-epithelialization process of skin repair and healing [Abate et al., 2021].

Fish skins are a by-product of the food industry and a rich source of collagen. Marine collagen has been noted to promote cell proliferation and migration of skin cells by augmenting various mediators in the stimulation of skin wound repair process [Chotphruethipong et al., 2021a; Hu et al., 2017; Yang et al., 2019b] and KSCs function [Thaweekitphathanaphakdee et al., 2019]. To date, bioactive peptides released from marine origin proteins, for example fish collagen have been reported to exhibit many biological effects including anti-inflammatory,

\footnotetext{
* Corresponding Author:

Email: wanida.su@psu.ac.th (W. Sukketsiri)
} 
anti-oxidant, anti-aging, and wound repair activities [Chotphruethipong et al., 2021a; Edgar et al., 2018; Huang et al., 2015]. Protein hydrolysates prepared by enzymatic processes from fish skin cause a reduction of aging and skin damage by photoaging [Chalamaiah et al., 2019; Chen et al., 2016; Edgar et al., 2018]. However, the information on the mechanism of hydrolyzed collagen from salmon skin (HCSS) effect on the proliferation and migration of human keratinocytes $\mathrm{HaCaT}$ remains unclear. Therefore, the main purpose of this study was to examine the effects of HCSS on keratinocyte proliferation and migration. The properties of KSC markers were also elucidated in this study.

\section{MATERIALS AND METHODS}

\section{Salmon skin preparation}

Frozen salmon skins were obtained from King-fisher Holdings Co., Ltd., Songkhla, Thailand. The skins at $3 \times 3 \mathrm{~cm}^{2}$ were applied with $\mathrm{NaOH}(100 \mathrm{mM})$ and subsequently washed until neutral pH was reached [Chotphruethipong et al., 2019]. Alkali-treated skins were saturated in 10 volumes of $100 \mathrm{mM}$ citric acid for $2 \mathrm{~h}$, followed by washing with tap water until wash water became neutral [Chotphruethipong et al., 2019]. The resulting swollen skins were utilized for hydrolyzed collagen preparation.

\section{Preparation of hydrolyzed collagen from salmon skin (HCSS) and analysis of amino acid composition}

HCSS was prepared using two-step enzymatic hydrolysis. Firstly, the swollen skins were treated with papain (3\% of solid content of fish skin) as tailored by Benjakul et al. [2018a]. The reaction was performed at $40^{\circ} \mathrm{C}$ for $3 \mathrm{~h}$ and subsequently terminated by heating at $90^{\circ} \mathrm{C}$ for $15 \mathrm{~min}$. Thereafter, Alcalase ( $2 \%$ of solid content of fish skin) was added into the mixture, followed by hydrolysis at $50^{\circ} \mathrm{C}$ for $2 \mathrm{~h}$. After hydrolysis, the inactivation was done at $90^{\circ} \mathrm{C}$ for $15 \mathrm{~min}$. The obtained hydrolyzed collagen was filtered, and the filtrate was concentrated with the solid content of $10 \%$ according to the method of Benjakul et al. [2018a]. The resulting concentrate was subjected to drying using a spray-dryer [Benjakul et al., 2018a]. Salmon hydrolyzed collagen powder was packed in ziplock bag and stored at $-40^{\circ} \mathrm{C}$ until used for analyses. The content of amino acids in HCSS was determined as detailed by Benjakul et al. [2018b]. Briefly, HCSS was hydrolyzed under reduced pressure in $4 \mathrm{M}$ methanesulphonic acid containing $0.2 \%(v / v) 3$-(2-aminoethyl)indole at $115^{\circ} \mathrm{C}$ for $24 \mathrm{~h}$ and neutralized with $3.5 \mathrm{M}$ sodium hydroxide. Digest was diluted with $0.2 \mathrm{M}$ citrate buffer ( $\mathrm{pH}$ 2.2). An aliquot of $0.4 \mathrm{~mL}$ was analyzed using an amino acid analyzer (MLC-703; Atto Co., Tokyo, Japan).

\section{Molecular weight (MW) distribution of HCSS}

Size exclusion chromatography was applied to determine MW distribution of HCSS powder by using a $2.5 \times 50 \mathrm{~cm}$ Sephadex G-25 gel filtration column (GE Healthcare Bio-Science AB, Uppsala, Sweden) [Chotphruethipong et al., 2021c]. The absorbance was detected at 220 and $280 \mathrm{~nm}$. Blue dextran $(2,000,000 \mathrm{Da})$ was used for void volume measurement. The MW standards were insulin chain B (3495.89 Da), vitamin $\mathrm{B}_{12}(1355.4 \mathrm{Da})$, glycine-tyrosine (238.25 Da), and tyrosine (181.2 Da). MW of the fraction was estimated from the plot between available partition coefficient $\left(\mathrm{K}_{\mathrm{av}}\right)$ and the logarithm of MW of the standards.

\section{Keratinocyte culture and cell viability assays of HCSS}

Human keratinocyte $\mathrm{HaCaT}$ cell line was purchased from the Cell Line Service, Heidelberg, Germany and cultured with $5 \% \mathrm{CO}_{2}$ atmosphere at $37^{\circ} \mathrm{C}$ in complete Dulbecco's Modified Eagle Medium (DMEM) supplemented with 10\% heatinactivated fetal bovine serum (FBS) (Gibco, Carlsbad, CA, USA), $2 \mathrm{mM}$ L-glutamine (Gibco), $100 \mathrm{U} / \mathrm{mL}$ penicillin, and $100 \mu \mathrm{g} / \mathrm{mL}$ streptomycin (Gibco). Keratinocyte $\mathrm{HaCaT}$ with a density of $1 \times 10^{4}$ cells/well were seeded in 96 -well plate. Then, keratinocyte $\mathrm{HaCaT}$ were exposed to $0,1,5,10,25,50,75$, $100,250,500$, and $1000 \mu \mathrm{g} / \mathrm{mL}$ of HCSS for 24,48 , and $72 \mathrm{~h}$. After each time of incubation, $500 \mu \mathrm{g} / \mathrm{mL}$ of 3-(4,5-dimethylthiazol-2-yl)-2,5-diphenyltetrazolium bromide (MTT) was applied into each well for $2 \mathrm{~h}$, the insoluble purple formazan was solubilized in dimethyl sulfoxide (DMSO). The cell viability was assessed at $570 \mathrm{~nm}$ with a microplate reader (Synergy $^{\mathrm{TM}}$ HT, Bio-tek Instruments, Winooski, VT, USA).

\section{Detection of cell proliferation by MTT and double stranded DNA (dsDNA) assay}

Keratinocyte $\mathrm{HaCaT}$ at $1 \times 10^{4}$ cells/well were cultured into 96-well plate. The cells were incubated with $0,50,100$, 500 , and $1000 \mu \mathrm{g} / \mathrm{mL}$ of HCSS for $24 \mathrm{~h}$. Cell proliferation was detected using a colorimetric MTT assay [Lü et al., 2012]. Briefly, $500 \mu \mathrm{g} / \mathrm{mL}$ of MTT was applied into each well for $2 \mathrm{~h}$. The insoluble purple formazan was solubilized in DMSO. The cell viability was assessed at $570 \mathrm{~nm}$ with a microplate reader $\left(\right.$ Synergy $^{\mathrm{TM}}$ HT). For dsDNA assay, cells were washed and incubated with $0.1 \%$ Triton X-100 for 10 min. Thereafter, the DNA content in keratinocyte $\mathrm{HaCaT}$ was measured using a dsDNA assay kit (Invitrogen, Carlsbad, California, USA). The intensity of fluorescence was measured at $485 \mathrm{~nm}$ (emission wavelength) and $535 \mathrm{~nm}$ (excitation wavelength) using a microplate reader (Synergy ${ }^{\mathrm{TM}} \mathrm{HT}$ ), and the percentage of $\mathrm{HaCaT}$ proliferation was calculated using the following formula:

$\begin{aligned} & \text { Cell } \\ & \text { proliferation }(\%)\end{aligned}=\frac{\text { DNA concentration of cells treated with HCSS }}{\text { DNA concentration of untreated cells }} \times 100$

\section{Detection of cell proliferation by total cellular protein content assay}

Keratinocyte $\mathrm{HaCaT}$ at a density of $1 \times 10^{4}$ cells/well was grown in 96-well plates. Then, cells were incubated with $0,50,100,500$, and $1000 \mu \mathrm{g} / \mathrm{mL}$ of HCSS for $24 \mathrm{~h}$. After $24 \mathrm{~h}$ of incubation, the cells were mixed with cold trichloroacetic acid (TCA) solution $(40 \%, w / v)$ and incubated for $1 \mathrm{~h}$ at $4^{\circ} \mathrm{C}$ as described by Thaweekitphathanaphakdee et al. [2019]. Sulforhodamine B (Sigma-Aldrich, St. Louis, MO, USA) solution $(0.04 \%, w / v)$ was added to each well and incubated for $1 \mathrm{~h}$ at room temperature. Thereafter, the cells were washed quickly with acetic acid $(1 \%, v / v)$, and then $0.01 \mathrm{M}$ Tris base was applied to each culture well. The absorbance at $510 \mathrm{~nm}$ was measured by a microplate reader $\left(\right.$ Synergy $^{\mathrm{TM}} \mathrm{HT}$ ) 
and the percentage of $\mathrm{HaCaT}$ proliferation was calculated using the following formula:

$\begin{aligned} & \text { Cell } \\ & \text { proliferation }(\%)\end{aligned}=\frac{\text { absorbance of mixture with HCSS }}{\text { absorbance of control }} \times 100$

\section{Wound healing assays}

The effect of HCSS on the migration of skin keratinocytes was evaluated using an in vitro scratch wound healing assay. The HaCaT keratinocytes $\left(3.5 \times 10^{5}\right.$ cells/well $)$ were grown in 6-well plates with DMEM medium containing $0.1 \%$ FBS. Prior to HCSS treatment $(0-1000 \mu \mathrm{g} / \mathrm{mL})$, a sterile P200 micropipette tip was used to make a wound space. The wound areas were captured on the image field at 3 points per line at 0 and $24 \mathrm{~h}$ using a phase-contrast microscope (Olympus IX70 Inverted Microscope, Olympus Corporation, Tokyo, Japan). The percentage of wound area was calculated as described by Singkhorn et al. [2018].

\section{Filopodia formation determination by phalloidin- -rhodamine staining}

After HCSS treatment at the concentrations of 0, 50, 100, 500 , and $1000 \mu \mathrm{g} / \mathrm{mL}$ for $24 \mathrm{~h}$, filopodia formation was determined as described previously [Singkhorn et al., 2018]. Briefly, the cells were fixed with paraformaldehyde $(4 \%, w / v)$, and the Triton-X100 (0.1\%) was added for cell permeabilization. After blocking with $2 \%$ bovine serum albumin (BSA) for $1 \mathrm{~h}$, keratinocyte HaCaT was incubated with phalloidin-rhodamine $(10 \mu \mathrm{g} / \mathrm{mL})$ and Hoechst $33342(10 \mu \mathrm{g} / \mathrm{mL})$ for $30 \mathrm{~min}$. The images were taken with a fluorescence microscope (Olympus IX70 with DP50), and the percentage of filopodia formation was determined using the following formula:

$\begin{aligned} & \text { Filopodia } \\ & \text { formation }(\%)\end{aligned}=\frac{\text { number of filopodia }}{\text { number of cells }} \times 100$

\section{Western blot analysis}

Keratinocyte $\mathrm{HaCa}$ T were exposed to HCSS at the concentrations of $0,50,100,500$, and $1000 \mu \mathrm{g} / \mathrm{mL}$ for $24 \mathrm{~h}$. The treated cells were then lysed in the lysis buffer containing protease and phosphatase inhibitor for $30 \mathrm{~min}$ at $4^{\circ} \mathrm{C}$. The lysed cells were collected and centrifuged at $14,024 \times g$ for $15 \mathrm{~min}$. Protein of the samples $(75 \mu \mathrm{g})$ was separated by $10 \%$ sodium dodecyl sulphate-polyacrylamide gel electrophoresis and moved onto nitrocellulose membranes. The non-specific protein of membranes was blocked using 5\% non-fat dry milk or $3 \%$ BSA in Tris-buffered saline containing $0.1 \%$ Tween 20 for $2 \mathrm{~h}$. The primary antibodies to FAK (Santa Cruz Biotechnology, Dallas, TX, USA; 1:1000), pFAK (Santa Cruz Biotechnology; 1:1000), Src (Abcam, Cambridge, UK; 1:1000), pSrc (Abcam; 1:1000), Akt (Santa Cruz Biotechnology; 1:1000), pAkt (Santa Cruz Biotechnology; 1:1000), RhoA (Abcam; 1:1000), Rac1 (Abcam; 1:1000), Cdc42 (Abcam; 1:1000), keratin 19 (Abcam; 1:1000), $\beta$-catenin (Abcam; 1:1000), and $\beta$-actin (Thermo Scientific, Waltham, MA, USA; 1:1,000) were incubated at $4^{\circ} \mathrm{C}$ overnight. The membranes were washed and incubated with secondary antibody conjugated to horseradish peroxidase at room temperature for $1 \mathrm{~h}$. The protein bands were exposed using an enhanced chemiluminescence
(ECL) western blotting detection reagent (Merck Millipore, Burlington, MA, USA) and analyzed by ImageJ software (Image Processing and Analysis in Java, National Institutes of Health, http://rsbweb.nih.gov/ij/).

\section{Statistical analysis}

The data were described as a mean \pm standard error of the mean (SEM). Statistical comparisons were made using one-way analysis of variance and Tukey post hoc test. Differences were considered significant when $p$ values were below $0.05(p<0.05)$.

\section{RESULTS AND DISCUSSION}

\section{Amino acid composition of hydrolyzed collagen from salmon skin (HCSS)}

As shown in Table 1, Gly was found as the dominant amino acid (19.66 g/100 g), followed by Pro (10.95 g/100 g), Gln/Glu (9.24 g/100 g), Ala (7.64 g/100 g), and Asn/Asp (7.49 g/100 g). Moreover, HCSS contained imino acids (Hyp and Pro) $(16.20 \mathrm{~g} / 100 \mathrm{~g})$. Gly is located at every third position in the collagen polypeptide chains in the presence of imino acids (Pro

TABLE 1. Relative amino acid composition of hydrolyzed collagen from salmon skins (HCSS).

\begin{tabular}{lc}
\hline Amino acid & Content (g/100 g) \\
\hline Alanine (Ala) & 7.64 \\
Arginine (Arg) & 7.00 \\
Asparagine/ Asparatic acid (Asn/Asp) & 7.49 \\
Cysteine (Cys) & 0.04 \\
Glutamine/Glutamic acid (Gln/Glu) & 9.24 \\
Glycine (Gly) & 19.66 \\
Histidine (His) & $\mathrm{ND}$ \\
Isoleucine (Ile) & 1.63 \\
Leucine (Leu) & 4.22 \\
Lysine (Lys) & 5.25 \\
Hydroxylysine (Hyl) & 0.76 \\
Methionine (Met) & 2.74 \\
Phenylalanine (Phe) & 3.08 \\
Hydroxyproline (Hyp) & 5.25 \\
Proline (Pro) & 10.95 \\
Serine (Ser) & 5.13 \\
Threonine (Thr) & 3.42 \\
Tyrosine (Tyr) & 3.50 \\
Valine (Val) & 2.89 \\
Tryptophan (Trp) & 0.11 \\
Total & 100.00 \\
\hline ND:Not & \\
\hline
\end{tabular}

ND: Not detected 


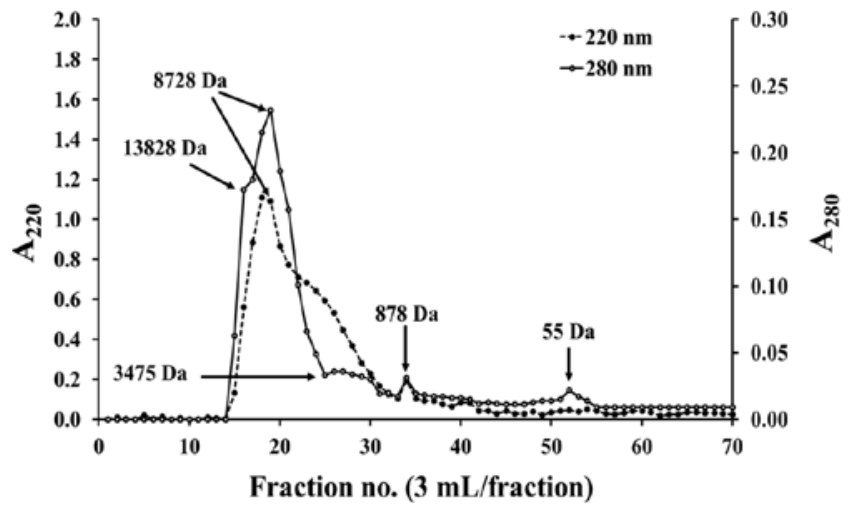

FIGURE 1. Elution profile by Sephadex G-25 size exclusion chromatography of hydrolyzed collagen powder from salmon skin.

and Hyp) as Gly-Pro-Hyp [Benjakul et al., 2018b] . A high content of hydrophobic amino acids, constituting approximately $50.07 \mathrm{~g} / 100 \mathrm{~g}$ of total amino acids, was also noted (Table 1). These amino acids played an essential role in the proliferation of skin cells [Chotphruethipong et al., 2021a,b]. Additionally, bioactive peptides from fish skin rich in Pro, Hyp, and Gly promoted the wound healing process [Chotphruethipong et al., 2021a]. Previous reports have shown that marine collagen from the skin of Nile tilapia has a high content of Gly-Pro-Hyp [Hu et al., 2017; Yang et al., 2019b].

\section{Size distribution of HCSS}

HCSS contained peptides with various molecular weights (MW) (Figure 1), with those having MWs of 8728, 878, and 55 Da being dominant. Peptides with high MW ( $>8 \mathrm{kDa})$ were also found (Figure 1). In general, the size of peptides is a vital factor affecting bioactivity of hydrolyzed collagen. The smaller size peptides exhibited higher bioactivities, especially cell proliferation activity [Chotphruethipong et al., $2021 \mathrm{c}, \mathrm{d}]$. Also, short chain peptides could be rapidly digested and absorbed in the human body [Morgan \& Breen, 2021].

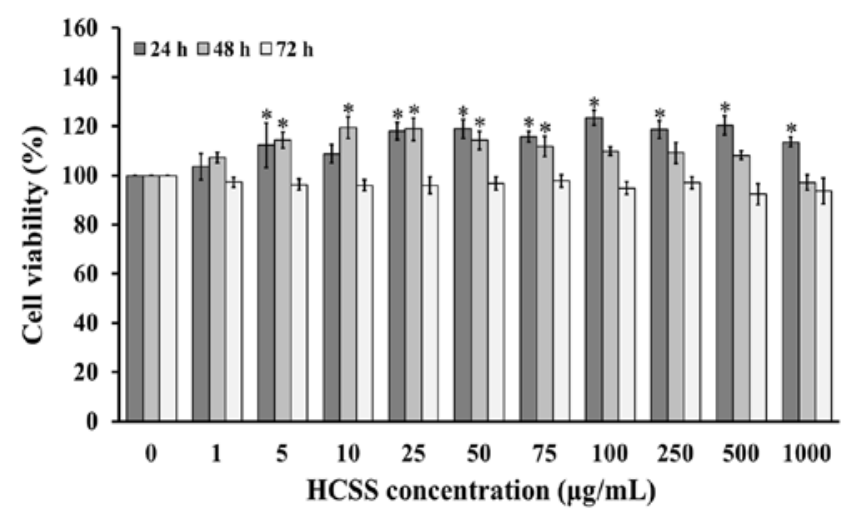

FIGURE 2. The viability of HaCaT keratinocytes after treatment with hydrolyzed collagen from salmon skin (HCSS) at concentrations of $0-1000 \mu \mathrm{g} / \mathrm{mL}$ for 24,48 , and $72 \mathrm{~h}$.

Results are presented as mean \pm standard error of the mean of four independent experiments $(n=4)$. The asterisk above bars indicates a significant difference between the HCSS treatment and the corresponding control without HCSS $(p<0.05)$.

\section{Effect of HCSS on cell viability of keratinocyte HaCaT}

Human keratinocyte cell lines are used as in vitro models to study the biological activities of molecules linked with dermatological conditions such as wound healing, contact dermatitis, psoriasis, or skin cancer. In our study, first, the effect of various concentrations of HCSS on keratinocyte $\mathrm{HaCaT}$ cell viability was assessed using the MTT assay to determine the cytotoxic effect and ensure the safe use of HCSS. As shown in Figure 2, exposure of the HaCaT cells to HCSS (5-1000 $\mu \mathrm{g} / \mathrm{mL})$ for $24 \mathrm{~h}$, and HCSS $(5-75 \mu \mathrm{g} / \mathrm{mL})$ for $48 \mathrm{~h}$ caused a significant $(p<0.05)$ increase in cell viability. However, HCSS at concentrations of $1-1000 \mu \mathrm{g} / \mathrm{mL}$ had no effect on the cell viability of keratinocyte $\mathrm{HaCaT}$ after $72 \mathrm{~h}$ of treatment. These findings proved the safety of all concentrations of HCSS as they did not cause the loss of cell viability even at the highest concentrations. Altogether, we could explain that the increment of cell viability may result from the high content of hydrophobic amino acids in HCSS (Table 1). Our findings were similar to the previous studies reporting that the hydrolyzed collagen from seabass skin significantly enhanced fibroblast and keratinocyte viability [Chotphruethipong et al., 2021a,b]. Research conducted by Yang et al. [2019b] also showed that peptides from Nibea japonica skin collagen increased cell viability of NIH-3T3 fibroblasts. Additionally, abalone collagen was observed to increase keratinocyte viability [Thaweekitphathanaphakdee et al., 2019]. Based on the results, we selected the HCSS concentrations of 50, 100, 500 , and $1000 \mu \mathrm{g} / \mathrm{mL}$ for further experiments.

\section{Proliferative effects of HCSS}

Cell proliferation involves crucial events at a cellular level in the second phase of wound repair process and also important for epidermis renewal [Martin \& Nunan, 2015; Yang et al., 2019a]. Therefore, HCSS at 50,100, 500, and $1000 \mu \mathrm{g} / \mathrm{mL}$ was further investigated for the proliferative activity in skin keratinocyte $\mathrm{HaCaT}$ cells. The cells were maintained in the growth medium (1\% FBS) in the presence or absence of HCSS at $50,100,500$, and $1000 \mu \mathrm{g} / \mathrm{mL}$ for 1 day. The MTT assay revealed that HCSS at 100,500 , and $1000 \mu \mathrm{g} / \mathrm{mL}$ significantly $(p<0.05)$ increased $\mathrm{HaCaT}$ proliferation after 1 day of cultivation in keratinocyte $\mathrm{HaCaT}$ (Figure 3A). Moreover, the proliferative activity of HCSS at 50,100, 500, and $1000 \mu \mathrm{g} / \mathrm{mL}$ was confirmed using the dsDNA assay and total cellular protein content determination because the MTT assay has some limitations in cell proliferation measurement [Van Tonder et al., 2015]. HCSS at 100, 500, and $1000 \mu \mathrm{g} / \mathrm{mL}$ induced a significant $(p<0.05)$ increase of cell proliferation in both assays (Figure $3 \mathrm{~B}$ and Figure $3 \mathrm{C}$ ), and the effect of HCSS on $\mathrm{HaCaT}$ cells was concentration dependent. Results from these three assays demonstrated that HCSS had a proliferative effect in keratinocytes. Our findings were in a good agreement with several previous studies in which fibroblast [Benjakul et al. 2018b; Chotphruethipong et al., 2021a; Yang et al., 2019b] and keratinocyte proliferation [Chotphruethipong et al., 2021b; Thaweekitphathanaphakdee et al., 2019] was promoted in response to peptides with hydrophobic amino acids (AAs) treatment. Sánchez \& Vázquez [2017] reported that the size of peptides, their AAs composition and sequence affect their cell proliferation potential. In addition, 
several studies reported that peptides of hydrolyzed collagen rich in Gly, Pro, and Ala affected the proliferation of fibroblast L929, MRC5, and bone marrow-mesenchymal stem (BMMS) cells [Benjakul et al. 2018b; Chotphruethipong et al., 2021a; Elango et al., 2019]. After $24 \mathrm{~h}$ of oral prolyl-hydroxyproline (a collagen-derived bioactive peptide) administration in rats, the radioactive $\left({ }^{14} \mathrm{C}\right)$ dipeptides of prolyl-hydroxyproline were observed in rats' osteoblasts, osteoclasts, dermal fibroblasts, epidermal cells, synovial cells, and chondrocytes [Kawaguchi et al., 2012]. Previous studies demonstrated also that Pro-Hyp affected the fibroblasts [Shigemura et al., 2009] and osteoblast

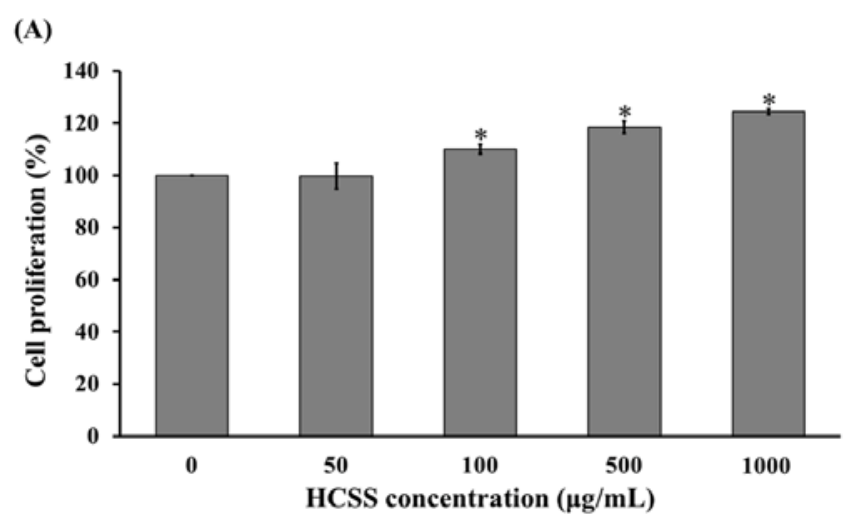

(B)

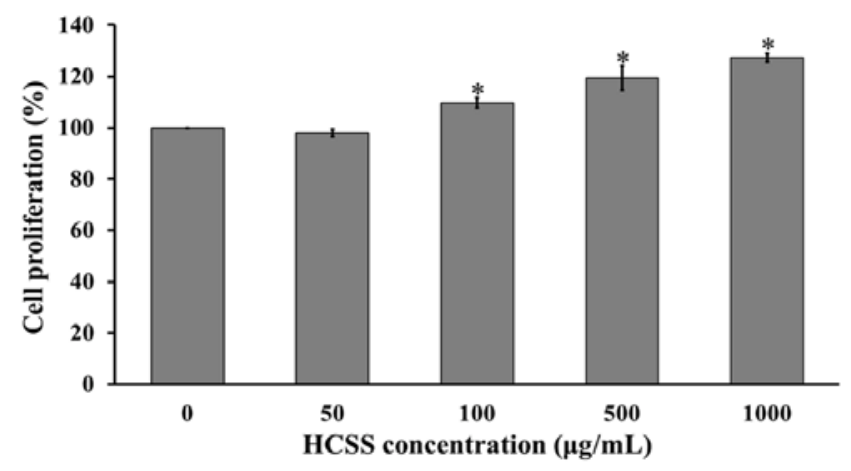

(C)

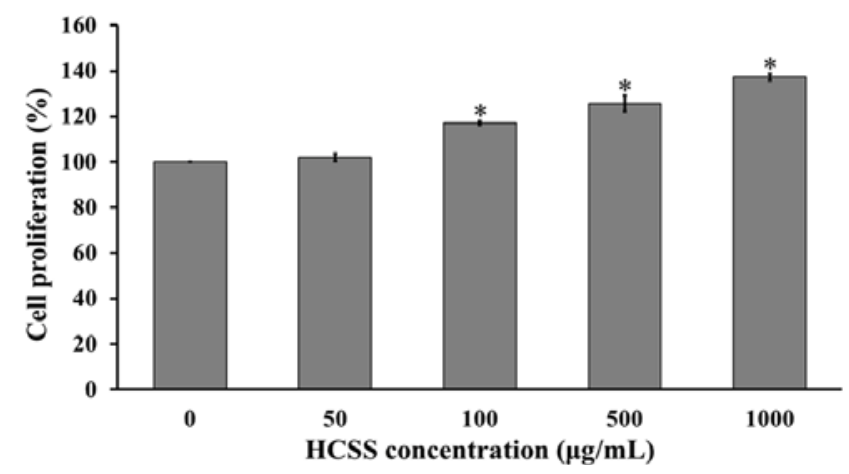

FIGURE 3. The proliferation of skin HaCaT keratinocytes after treatment with hydrolyzed collagen from salmon skin (HCSS) at concentrations of $0,50,100,500$ and $1000 \mu \mathrm{g} / \mathrm{mL}$ for $24 \mathrm{~h}$. (A) 3-(4,5-dimethylthiazol-2-yl)-2,5-diphenyltetrazolium bromide (MTT) assay, (B) double stranded DNA (dsDNA) assay and (C) total cellular protein assay.

Results are presented as mean \pm standard error of the mean of four independent experiments $(n=4)$. The asterisk above bars indicates a significant difference between the HCSS treatment and the corresponding control without HCSS $(p<0.05)$.
[Kimira et al., 2017] proliferation. In this study, we found higher levels of Gly, Pro, and Ala in HCSS consistent with the proliferation of skin keratinocyte HaCaT cells. Therefore, it can be assumed that Pro and Hyp of HCSS peptides may regulate keratinocyte proliferation.

\section{HCSS increases the migration and filopodia formation in keratinocytes HaCaT}

Besides cell proliferation, an appropriate keratinocyte migration is required for minor, superficial, and basic skin lesions for the second phase of wound healing. Keratinocytes are also involved in more complex pathological states, for example ulcers or pressure sores [Horikoshi et al., 2018]. Therefore, a wounded area was further determined to assess the potential effect of HCSS at 50, 100, 500, and $1000 \mu \mathrm{g} / \mathrm{mL}$ on the migratory activity of $\mathrm{HaCaT}$ cells. Based on the wound-healing assay, HCSS at 50, 100, 500, and $1000 \mu \mathrm{g} / \mathrm{mL}$ significantly decreased the wound area in a concentration dependent manner with $20.57 \pm 5.58,8.31 \pm 2.79,0.00 \pm 0.00$, and $0.00 \pm 0.00 \%$, respectively (Figure 4A and Figure 4B). A low concentration of HCSS supported the efficiency in wound closure by $70-80 \%$ as compared to the control. The wound area was completely closed after $24 \mathrm{~h}$ when HCSS was used at concentrations of 500 and $1000 \mu \mathrm{g} / \mathrm{mL}$. This result implied that HCSS could stimulate keratinocyte migration, especially at the high concentration. In general, collagen had a crucial role in wound repair by promoting the endothelial cells mobility to develop new blood vessels [Martin \& Nunan, 2015]. Thus, the granulation tissue development was increased, and wound area was declined [Chotphruethipong et al., 2021a]. Hyp, a specific component of collagen, is an important indicator to determine collagen deposition during wound healing process [Huang et al., 2015]. Chen et al. [2019] documented that fish collagen rich in Hyp could accelerate wound healing process of Sprague Dawley rats. Similarly, an earlier report claimed that collagen hydrolysates rich in Gly, Pro, and Ala had a potential activity in wound closure [Chotphruethipong et al., 2021a]. Thus, amino acids, especially Gly and Pro, found in HCSS might promote keratinocyte migration as ascertained by the decreased wound gap. Thus, it can be postulated that an increase in the rate of keratinocytes proliferation and migration undoubtedly leads to fast wound healing.

The cytoskeleton is one of essential constituents in wound healing requiring the shrinkage of actomyosin, cell migration and enlistment of repair systems [Abreu-Blanco et al., 2012]. The migration of cell involves the formation of cell protrusion, for example lamellipodia and filopodia [Singkhorn et al., 2018]. This is the first study to elucidate the protrusion of cell that facilitated cell migration in response to HCSS treatment in keratinocytes. Keratinocyte HaCaT cells were exposed to HCSS (50-1000 $\mu \mathrm{g} / \mathrm{mL})$ for $24 \mathrm{~h}$. Our results showed that 100 , 500 , and $1000 \mu \mathrm{g} / \mathrm{mL}$ HCSS treatment significantly enhanced the number of filopodia per cells as compared with the control (Figure 4C and Figure 4D). The highest activity was presented in cells treated with HCSS at $1000 \mu \mathrm{g} / \mathrm{mL}$. Taken together, our results revealed the migratory activities of HCSS in keratinocytes. This result was consistent with wound area (Figure 4A and Figure 4B) as evidenced by the increased formation of filopodia, particularly at the HCSS concentrations 
(A)

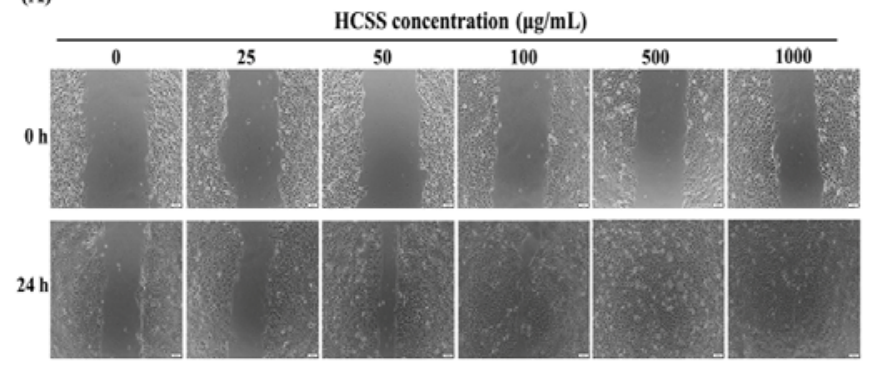

(B)

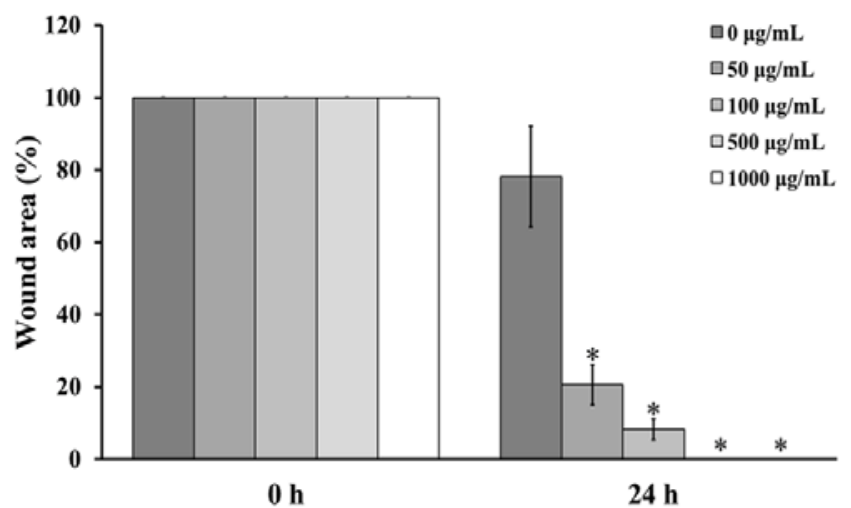

(C)

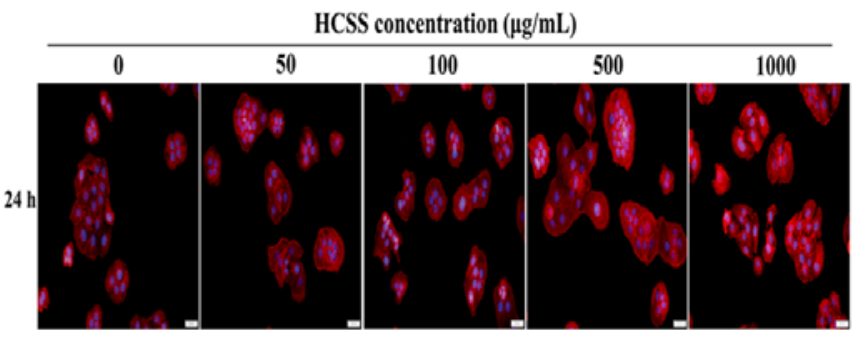

(D)

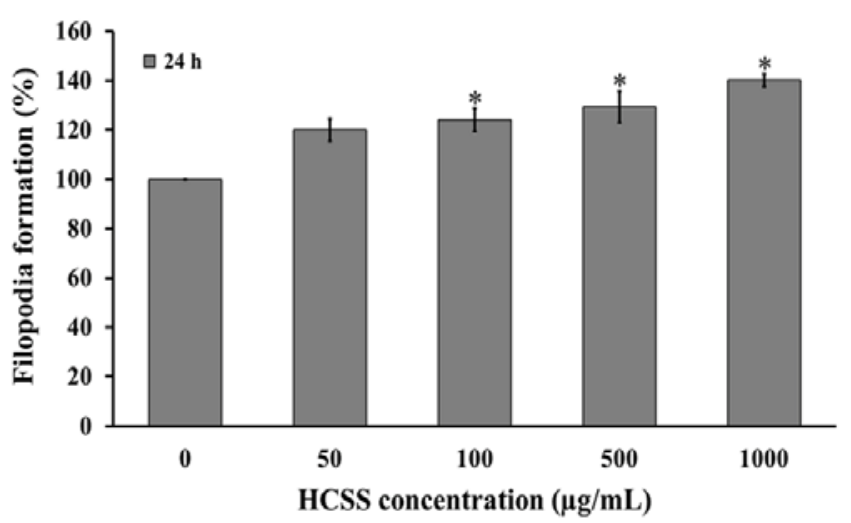

FIGURE 4. The migration activities and filopodia formation of skin HaCaT keratinocytes after treatment with hydrolyzed collagen from salmon skin (HCSS) at concentrations of $0,50,100,500$ and $1000 \mu \mathrm{g} / \mathrm{mL}$ for $24 \mathrm{~h}$. (A) wound healing assay, (B) the percentage of wound area, (C) phalloidin-rhodamine stained for filopodia (scale bar $=50 \mu \mathrm{m}$ ), and (D) percentage of filopodia formation.

Results are presented as mean \pm standard error of the mean of four independent experiments $(n=4)$. The asterisk above bars indicates a significant difference between the HCSS treatment and the corresponding control without HCSS $(p<0.05)$.

of 100,500 , and $1000 \mu \mathrm{g} / \mathrm{mL}$. Our findings agree with results of previous studies which have shown that hydrolyzed collagen from fish skin increased the formation of lamellipodia in fibroblasts [Chotphruethipong et al., 2021a]. Altogether, we could explain that the upregulation of filopodia formation in this study may be due to the AAs content in hydrolyzed collagen and may subsequently contribute to the increased keratinocyte migration in the wound healing process.

\section{HCSS increases cell migration and filopodia formation via focal adhesion kinase (FAK)/steroid receptor coactivator (Sre) activation}

In the present study, the migratory activity of skin keratinocytes was induced by HCSS administration. Several signaling molecules have been identified and found to be necessary in the control of cell migration, extension, and cytoskeleton contraction, for example, FAK, Src, protein kinase B (Akt), Ras-related C3 botulinum toxin substrate 1 (Rac1), Ras homolog family member A (RhoA), and cell division control protein 42 (Cdc42) [Masraksa et al., 2020; Ritto et al., 2017; Singkhorn et al., 2018]. The upstream regulatory cell signals of cell migration controllers, such as FAK, Src, and Akt, were further analyzed. The results revealed that HCSS administration increased the expression of pFAK (phosphorylated at Tyr397) and pSrc (phosphorylated at Tyr418), in keratinocyte $\mathrm{HaCaT}$ at 100, 500, and $1000 \mu \mathrm{g} / \mathrm{mL}$ (Figure 5A and Figure 5B). However, the pAkt (phosphorylated at Ser473) was not affected by the HCSS treatment. FAK and Src are important for reepithelialization during the wound repair process [Seo et al., 2018; Singkhorn et al., 2018]. In addition, stimulation of FAK and Src complex activates keratinocytes migration in epidermal wound healing [Petpiroon et al., 2015; Seo et al., 2018; Singkhorn et al., 2018]. Nevertheless, this is the first study to examine the mechanism of HCSS induced keratinocyte migration through the FAK-Src complex pathway activation. Few studies reported that the amino acid domain containing Asn, Gly, Gln, and Ala in collagen can interact with $\alpha_{2} \beta_{1}$ integrin on the cell membrane that is involved in the activation of the FAK-c-Jun N-terminal kinase (JNK) pathway [Chiu et al., 2014]. Thus, we could explain that the activation of FAK-Src by HCSS may result from the presence of Asn, Gly, Gln, and Ala in hydrolyzed collagen which was found in the high level in our study.

Our previous reports demonstrated that Cdc42, Rac1, and RhoA proteins were involved in the filopodia formation and migration of skin keratinocytes [Ritto et al., 2017; Singkhorn et al., 2018]. In order to authenticate the mechanism of HCSS effect on the migration stimulation in keratinocyte, we used western blot to examine the important downstream Cdc42, Rac1, and RhoA proteins expression involved in the migration process. In this study, $\mathrm{Cdc} 42, \mathrm{Rac1}$, and RhoA proteins expression was established to be raised in response to HCSS treatment at the concentrations 100, 500, and $1000 \mu \mathrm{g} / \mathrm{mL}$ (Figure 5C and Figure 5D). To our knowledge, this is the first study that described the downstream Cdc42, Rac1 and RhoA proteins activation by HCSS. Thus, we suggest that HCSS 
(A)

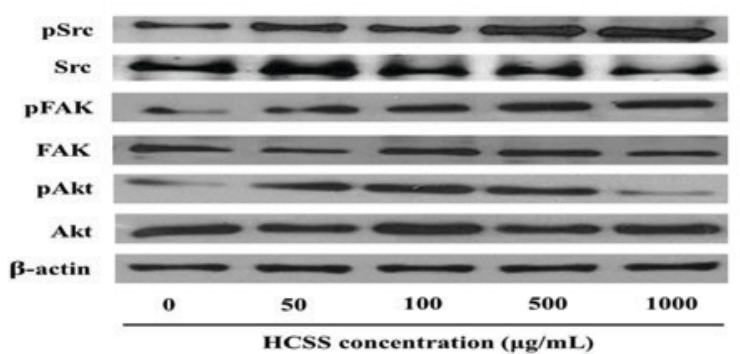

(B)

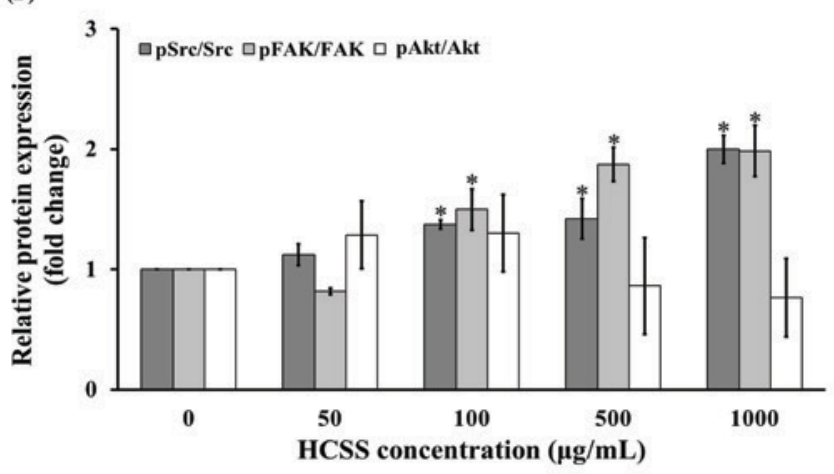

(C)

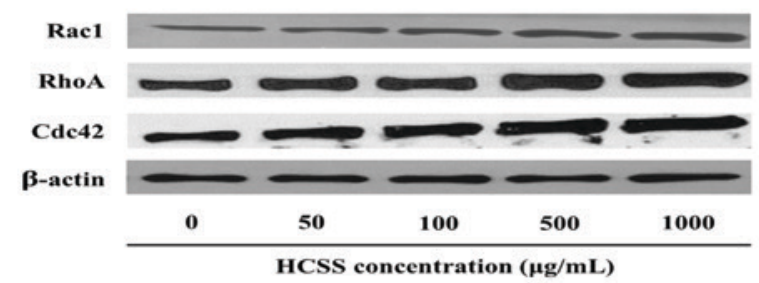

(D)

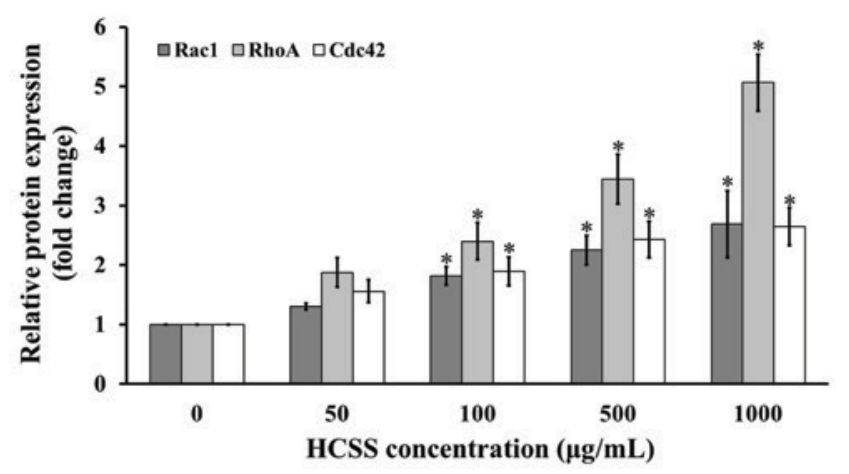

FIGURE 5. The migration protein expression of skin HaCaT keratinocytes after treatment with hydrolyzed collagen from salmon skin (HCSS) at concentrations of $0,50,100,500$ and $1000 \mu \mathrm{g} / \mathrm{mL}$ for $24 \mathrm{~h}$. (A) western blotting indicating the expression of pSrc, Src, pFAK, FAK, pAkt, and Akt, (B) the relative expression of $\mathrm{pSrc} / \mathrm{Src}$, pFAK/FAK, and pAkt/Akt, (C) western blotting indicating the expression of Rac1, RhoA, and Cdc42, and (D) the relative expression of Rac1, Cdc42, and RhoA.

Results are presented as mean \pm standard error of the mean of four independent experiments $(n=4)$. The asterisk above bars indicates a significant difference between the HCSS treatment and the corresponding control without HCSS $(p<0.05)$.

regulated cell migration and cytoplasmic protrusions formation of skin by activating FAK/Src upstream pathways, and Rac1, Cdc42, and RhoA downstream pathway.

\section{HCSS increases the expression of stem cell markers}

Keratinocyte stem cells (KSCs) are accountable for sustaining epidermal homeostasis and healing the tissue damages [Fuchs, 2008; Pincelli \& Marconi, 2010; Sotiropoulou \& Blanpain, 2012]. Several evidence indicate that KSCs contain various proteins which demonstrated the powerful function in maintaining stem cell-like phenotypes, for example keratin 19, $\beta$-catenin, and others [Abbas et al., 2011; Leng et al., 2020]. The present study showed that HCSS treatment at the concentrations 100,500 , and $1000 \mu \mathrm{g} / \mathrm{mL}$ significantly enhanced keratin 19 and $\beta$-catenin protein expression in keratinocyte $\mathrm{HaCaT}$ cells when compared to the untreated control (Figure 6A and Figure 6B). Our results were similar to those from the previous studies reporting that the collagen extract from abalone caused an increase in KSCs marker expression, such as ALDH1A1, keratin 19, and $\beta$-catenin in keratinocyte HaCaT cells [Thaweekitphathanaphakdee et al., 2019]. In addition, collagen type I enhanced the properties of stem cell-like phenotype by the $\alpha_{2} \beta_{1}$-integrin activation [Kirkland, 2009]. Integrin is a cell surface receptor that plays a crucial role in maintaining several signaling cascades such as Akt [Desgrosellier \& Cheresh, 2010] and Wnt/ $\beta$-catenin [Crampton et al., 2009; Leng et al., 2020]; thereby mediates cell survival and proliferation, and stimulates stemness of cells [Leng et al., 2020]. It is possible that HCSS may activate stemness
(A)

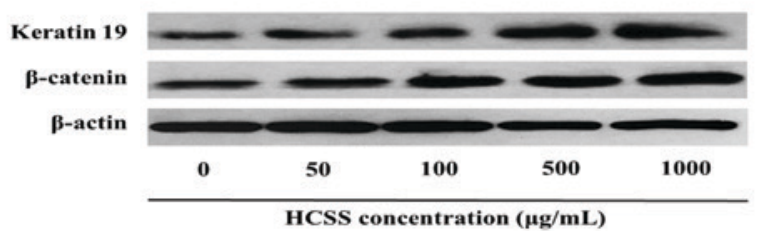

(B)

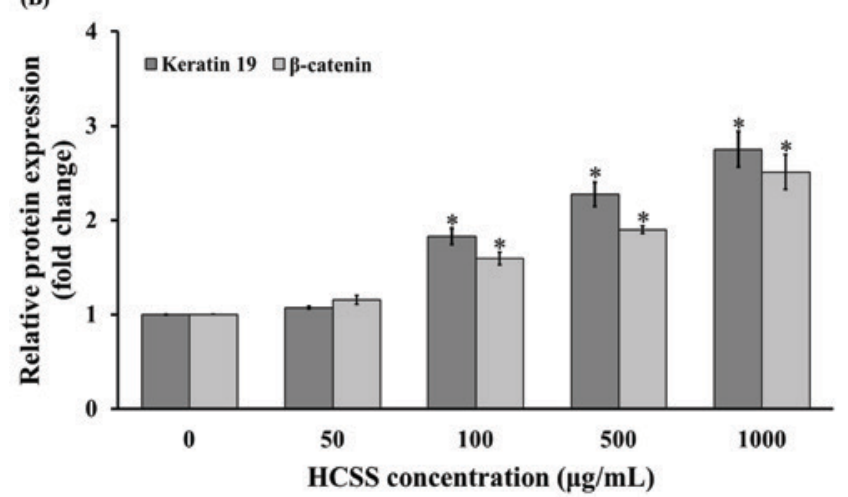

FIGURE 6. The expression of stem cell markers in skin HaCaT keratinocytes after treatment with hydrolyzed collagen from salmon skin (HCSS) at concentrations of $0,50,100,500$ and $1000 \mu \mathrm{g} / \mathrm{mL}$ for $24 \mathrm{~h}$. (A) western blotting indicating the expression of keratin 19 and $\beta$-catenin, and (B) the relative expression of keratin 19 and $\beta$-catenin.

Results are presented as mean \pm standard error of the mean of four independent experiments $(n=4)$. The asterisk above bars indicates a significant difference between the HCSS treatment and the corresponding control without HCSS $(p<0.05)$. 
of keratinocytes by $\beta$-catenin-dependent mechanism. Our results add to the existing knowledge that HCSS improves the keratinocytes stemness properties, which are essential for epidermal homeostasis and skin barrier function [Fuchs, 2008; Pincelli \& Marconi, 2010; Sotiropoulou \& Blanpain, 2012].

\section{CONCLUSIONS}

Fish skins, being by-products of the food industry, represent a viable material for producing collagen hydrolysates. A hydrolyzed collagen from salmon skins (HCSS) significantly activated the migration of keratinocytes, a predominant cell type in the epidermis, by the activation FAK-Src upstream pathway and Rac1, RhoA, and Cdc42 downstream pathway. In addition, HCSS significantly increased the expression levels of stem cell markers, which are crucial factors for keratinocyte stem cell's function. Taken together, HCSS has been highlighted to elicit the beneficial effect which may have a promising utilization for wound healing, skin repair, and skin barrier function.

\section{ACKNOWLEDGEMENTS}

We thank Publication clinic, Prince of Songkla University for the assistance in manuscript language editing.

\section{RESEARCH FUNDING}

This research was funded by Participation in the Partnership Program in Production of Graduates in Master's Degree between the Thailand Institute of Scientific and Technological Research (TISTR) and Educational Institutions (6110220098).

\section{CONFLICT OF INTERESTS}

The authors declare no conflict of interest.

\section{ORCID IDs}

S. Tanasawet https://orcid.org/0000-0002-6877-9298

S. Benjakul https://orcid.org/0000-0001-9433-3671

W. Sukketsiri https://orcid.org/0000-0003-0836-1487

\section{REFERENCES}

1. Abate, M., Citro, M., Pisanti, S., Caputo, M., Martinelli, R. (2021). Keratinocytes migration promotion, proliferation induction, and free radical injury prevention by 3-hydroxytirosol. International Journal of Molecular Sciences, 22(5), art. no. 2438.

https://doi.org/10.3390/ijms22052438

2. Abbas, O., Richards, J.E., Yaar, R., Mahalingam, M. (2011). Stem cell markers (cytokeratin 15, cytokeratin 19 and p63) in in situ and invasive cutaneous epithelial lesions. Modern Pathology, 24, 90-97.

https://doi.org/10.1038/modpathol.2010.180

3. Abreu-Blanco, M.T., Watts, J.J., Verboon, J.M., Parkhurst, S.M. (2012). Cytoskeleton responses in wound repair. Cellular and Molecular Life Sciences, 69, 2469-2483.

https://doi.org/10.1007/s00018-012-0928-2
4. Baroni, A., Buommino, E., De Gregorio, V., Ruocco, E., Ruocco, V., Wolf, R. (2012). Structure and function of the epidermis related to barrier properties. Clinics in Dermatology, 30(3), 257-262. https://doi.org/10.1016/j.clindermatol.2011.08.007

5. Benjakul, S., Karnjanapratum, S., Visessanguan, W. (2018a). Production and characterization of odorless antioxidative hydrolyzed collagen from seabass (Lates calcarifer) skin without descaling. Waste and Biomass Valorization, 9, 549-559.

https://doi.org/10.1007/s12649-017-0008-9

6. Benjakul, S., Karnjanapratum, S., Visessanguan, W. (2018b). Hydrolysed collagen from Lates calcarifer skin: its acute toxicity and impact on cell proliferation and collagen production of fibroblasts. International Journal of Food Science \& Technology, 53(8), 1871-1879.

https://doi.org/10.1111/ijfs.13772

7. Chalamaiah, M., Ulug, S.K., Hong, H., Wu, J.P. (2019). Regulatory requirements of bioactive peptides (protein hydrolysates) from food proteins. Journal of Functional Foods, 58, 123-129.

https://doi.org/10.1016/j.jf.2019.04.050

8. Chen, T., Hu, H., Fan, Y., Wang, S., Chen, Q., Si, L., Li, B. (2016). Protective effect of gelatin peptides from pacific cod skin against photoaging by inhibiting the expression of MMPs via MAPK signaling pathway. Journal of Photochemistry and Photobiology B: Biology, 165, 34-41.

https://doi.org/10.1016/j.jphotobiol.2016.10.015

9. Chen, J., Gao, K., Liu, S., Wang, S., Elango, J., Bao, B., Dong, J., Liu, N., Wu, W. (2019). Fish collagen surgical compress repairing characteristics on wound healing process in vivo. Marine Drugs, 17(1), art. no. 33 .

https://doi.org/10.3390/md17010033

10. Chiu, L.H., Lai, W.F., Chang, S.F., Wong, C.C., Fan, C.Y., Fang, C.L., Tsai, Y.H. (2014). The effect of type II collagen on MSC osteogenic differentiation and bone defect repair. Biomaterials, 35(9), 2680-2691.

https://doi.org/10.1016/j.biomaterials.2013.12.005

11. Chotphruethipong, L., Aluko, R.E., Benjakul, S. (2019). Hydrolyzed collagen from porcine lipase-defatted seabass skin: antioxidant, fibroblast cell proliferation, and collagen production activities. Journal of Food Biochemistry, 43(5), art. no. e12825.

https://doi.org/10.1111/jfbc.12825

12. Chotphruethipong, L., Sukketsiri, W., Aluko, R.E., Sae-leaw, T., Benjakul, S. (2021a). Effect of hydrolyzed collagen from defatted Asian sea bass (Lates calcarifer) skin on fibroblast proliferation, migration and antioxidant activities. Journal of Food Science and Technology, 58, 541-551.

https://doi.org/10.1007/s13197-020-04566-4

13. Chotphruethipong, L., Sukketsiri, W., Battino, M., Benjakul, S. (2021b). Conjugate between hydrolyzed collagen from defatted seabass skin and epigallocatechin gallate (EGCG): characteristics, antioxidant activity and in vitro cellular bioactivity. RSC Advances, 11, 2175-2184.

https://doi.org/10.1039/DORA07135H

14. Chotphruethipong, L., Binlateh, T., Hutamekalin, P., Sukketsiri, W., Aluko, R.E., Benjakul, S. (2021c). In vitro antioxidant and wound-healing activities of hydrolyzed collagen from defatted Asian sea bass skin as influenced by different enzyme types and hydrolysis processes. RSC Advances, 11, 18144-18151. https://doi.org/10.1039/D1RA03131G 
15. Chotphruethipong, L., Binlateh, T., Hutamekalin, P., Aluko, R.E., Tepaamorndech, S., Zhang, B., Benjakul, S. (2021d). Impact of hydrolyzed collagen from defatted sea bass skin on proliferation and differentiation of preosteoblast MC3T3-E1 cells. Foods, 10(7), art. no. 1476.

https://doi.org/10.3390/foods10071476

16. Crampton, S.P., Wu, B., Park, E.J., Kim, J.H., Solomon, C., Waterman, M.L., Hughes, C.C. (2009). Integration of the $\beta$-catenin-dependent Wnt pathway with integrin signaling through the adaptor molecule Grb2. PLoS One, 4, art. no. e7841.

https://doi.org/10.1371/journal.pone.0007841

17. Desgrosellier, J.S., Cheresh, D.A. (2010). Integrins in cancer: biological implications and therapeutic opportunities. Nature Reviews Cancer, 10, 9-22. https://doi.org/10.1038/nrc2748

18. Edgar, S., Hopley, B., Genovese, L., Sibilla, S., Laight, D., Shute, J. (2018). Effects of collagen-derived bioactive peptides and natural antioxidant compounds on proliferation and matrix protein synthesis by cultured normal human dermal fibroblasts. Scientific Reports, 8, art. no. 10474.

https://doi.org/10.1038/s41598-018-28492-w

19. Elango, J., Robinson, J., Zhang, J., Bao, B., Ma, N., de Val, J.E.M.S., Wu, W. (2019). Collagen peptide upregulates osteoblastogenesis from bone marrow mesenchymal stem cells through MAPK- Runx2. Cells, 8(5), art. no. 446.

https://doi.org/10.3390/cells8050446

20. Fuchs, E. (2008). Skin stem cells: rising to the surface. Journal of Cell Biology, 180(2), 273-284.

https://doi.org/10.1083/jcb.200708185

21. Horikoshi, Y., Kamizaki, K., Hanaki, T., Morimoto, M., Kitagawa, Y., Nakaso, K., Kusumoto, C., Matsura, T. (2018). $\alpha$-Tocopherol promotes $\mathrm{HaCaT}$ keratinocyte wound repair through the regulation of polarity proteins leading to the polarized cell migration. BioFactors, 44(2), 180-191.

https://doi.org/10.1002/biof.1414

22. Hu, Z., Yang, P., Zhou, C., Li, S., Hong, P. (2017). Marine collagen peptides from the skin of nile tilapia (Oreochromis niloticus): characterization and wound healing evaluation. Marine Drugs, 15(4), art. no. 102.

https://doi.org/10.3390/md15040102

23. Huang, R., Li, W., Lv, X., Lei, Z., Bian, Y., Deng, H., Wang, H., Li, J., Li, X. (2015). Biomimetic LBL structured nanofibrous matrices assembled by chitosan/collagen for promoting wound healing. Biomaterials, 53, 58-75.

https://doi.org/10.1016/j.biomaterials.2015.02.076

24. Kawaguchi, T., Nanbu, P.N., Kurokawa, M. (2012). Distribution of prolylhydroxyproline and its metabolites after oral administration in rats. Biological and Pharmaceutical Bulletin, 35(3), 422-427. https://doi.org/10.1248/bpb.35.422

25. Kimira, Y., Odaira, H., Nomura, K., Taniuchi, Y., Inoue, N., Nakatani, S., Shimizu, J., Wada, M., Mano, H. (2017). Collagen-derived dipeptide prolylhydroxyproline promotes osteogenic differentiation through Foxg1. Cellular \& Molecular Biology Letters, 22 , art. no. 27.

https://doi.org/10.1186/s11658-017-0060-2

26. Kirkland, S.C. (2009). Type I collagen inhibits differentiation and promotes a stem cell-like phenotype in human colorectal carcinoma cells. British Journal of Cancer, 101, 320-326.

https://doi.org/10.1038/sj.bjc.6605143
27. Leng, L., Ma, J., Lv, L., Wang, W., Gao, D., Zhu, Y., Wu, Z. (2020). Both Wnt signaling and epidermal stem cell-derived extracellular vesicles are involved in epidermal cell growth. Stem Cell Research \& Therapy, 11, art. no. 415. https://doi.org/10.1186/s13287-020-01933-y

28. Lü, L., Zhang, L., Wai, M.S.M., Yew, D.T.W., Xu, J. (2012). Exocytosis of MTT formazan could exacerbate cell injury. Toxicology in Vitro, 26(4), 636-644.

https://doi.org/10.1016/j.tiv.2012.02.006

29. Martin, P., Nunan, R. (2015). Cellular and molecular mechanisms of repair in acute and chronic wound healing. British Journal of Dermatology, 173(2), 370-378.

https://doi.org/10.1111/bjd.13954

30. Masraksa, W., Tanasawet, S., Hutamekalin, P., Wongtawatchai, T., Sukketsiri, W. (2020). Luteolin attenuates migration and invasion of lung cancer cells via suppressing focal adhesion kinase and non-receptor tyrosine kinase signaling pathway. Nutrition Research and Practice, 14(2), 127-133.

https://doi.org/10.4162/nrp.2020.14.2.127

31. Morgan, P.T., Breen, L. (2021). The role of protein hydrolysates for exercise-induced skeletal muscle recovery and adaptation: a current perspective. Nutrition \& Metabolism, 18, art. no. 44. https://doi.org/10.1186/s12986-021-00574-z

32. Petpiroon, N., Suktap, C., Pongsamart, S., Chanvorachote, P., Sukrong, S. (2015). Kaempferol-3-O-rutinoside from Afgekia mahidoliae promotes keratinocyte migration through FAK and Rac 1 activation. Journal of Natural Medicines, 69, 340-348. https://doi.org/10.1007/s11418-015-0899-3

33. Pincelli, C., Marconi, A. (2010). Keratinocyte stem cells: friends and foes. Journal of Cellular Physiology, 225(2), 310-315. https://doi.org/10.1002/jcp.22275

34. Ritto, D., Tanasawet, S., Singkhorn, S., Klaypradit, W., Hutamekalin, P., Tipmanee, V., Sukketsiri, W. (2017). Astaxanthin induces migration in human skin keratinocytes via Rac1 activation and RhoA inhibition. Nutrition Research and Practice, 11(4), 275-280.

https://doi.org/10.4162/nrp.2017.11.4.275

35. Sánchez, A., Vázquez, A. (2017). Bioactive peptides: A review. Food Quality and Safety, 1, 29-46. https://doi.org/10.1093/fqsafe/fyx006

36. Shigemura, Y., Iwai, K., Morimatsu, F., Iwamoto, T., Mori, T., Oda, C., Taira, T., Park, E.Y., Nakamura, Y., Sato, K. (2009). Effect of prolyl-hydroxyproline (Pro-Hyp), a food-derived collagen peptide in human blood, on growth of fibroblasts from mouse skin. Journal Agricultural and Food Chemistry, 57(2), 444-449. https://doi.org/10.1021/jf802785h

37. Singkhorn, S., Tantisira, M.H., Tanasawet, S., Hutamekalin, P., Wongtawatchai, T., Sukketsiri, W. (2018). Induction of keratinocyte migration by ECa 233 is mediated through FAK/Akt, ERK, and p38 MAPK signaling. Phytotherapy Research, 32(7), 1397-1403. https://doi.org/10.1002/ptr.6075

38. Seo, G.Y., Hyun, C., Koh, D., Park, S., Lim, Y., Kim, Y.M., Cho, M. (2018). A novel synthetic material, BMM, accelerates wound repair by stimulating re-epithelialization and fibroblast activation. International Journal of Molecular Sciences, 19(4), art. no. 1164 .

https://doi.org/10.3390/ijms19041164 
39. Sotiropoulou, P.A., Blanpain, C. (2012). Development and homeostasis of the skin epidermis. Cold Spring Harbor Perspectives in Biology, 4, art. no. a008383.

https://doi.org/10.1101/cshperspect.a008383

40. Thaweekitphathanaphakdee, S., Chanvorachote, P., Prateepchinda, S., Khongkow, M., Sucontphunt, A. (2019). Abalone collagen extracts potentiate stem cell properties of human epidermal keratinocytes. Marine Drugs, 17(7), art. no. 424.

https://doi.org/10.3390/md17070424

41. Van Tonder, A., Joubert, A.M., Cromarty, A.D. (2015). Limitations of the 3-(4,5-dimethylthiazol-2-yl)-2,5-diphenyl-2H-tetrazolium bromide (MTT) assay when compared to three commonly used cell enumeration assays. BMC Research Notes, 8, art. no. 47.

https://doi.org/10.1186/s13104-015-1000-8
42. Wickett, R.R., Visscher, M.O. (2006). Structure and function of the epidermal barrier. American Journal of Infection Control, 34(10), Suppl., S98-S110.

https://doi.org/10.1016/j.ajic.2006.05.295

43. Wikramanayake, T.C., Stojadinovic, O., Tomic-Canic, M. (2014). Epidermal differentiation in barrier maintenance and wound healing. Advances in Wound Care, 3(3), 272-280. https://doi.org/10.1089/wound.2013.0503

44. Yang, R., Liu, F., Wang, J., Chen, X., Xie, J., Xiong, K. (2019a). Epidermal stem cells in wound healing and their clinical applications. Stem Cell Research \& Therapy, 10, art. no. 229. https://doi.org/10.1186/s13287-019-1312-z

45. Yang, F., Jin, S., Tang, Y. (2019b). Marine collagen peptides promote cell proliferation of NIH-3T3 fibroblasts via NF- $\mathrm{BB}$ signaling pathway. Molecules, 24(22), art. no. 4201. https://doi.org/10.3390/molecules24224201 